\title{
SEED PROCESSING
}

\section{P. O'Neill}

Co-operation, tolerance, communication and planning are necessary at harvest time, and can help minimise delays and difficulties when off-loading seed at the processing plant. In normal circumstances the first areas of concern on the seed's arrival into store are the condition of the seed and the certification requirements. These areas have been dealt with in other papers, so this paper will concentrate on the post-harvest treatment of seed.

A common fault in ryegrass harvesting is to. include a large amount of light trash, straw and empty glumes in the sample. This creates problems when dressing, for although the rubbish can be removed relatively easily and the weight loss may not be excessive, production from the plant is likely to be reduced because of the volume passing through the machine. Furthermore, in an effort not to lose good seed the operator may tend to cut back on 'blast'. This in turn may result in an inferior Purity and Germination test because of the inert matter content.

Other problems that can involve high dressing losses are the lack of management in the field and excessive thrashing resulting in unnecessary weed or other crop contaminants. For instance, if goosegrass (Bromus mollis) is damaged at harvesting and the tail or awn broken or removed, it is extremely difficult to dress out. Extraction of goosegrass from ryegrass is usually attempted with the use of screens and cylinders. As the goosegrass seed is flared and normal- ryegrass is not, the correct-sized screen allows ryegrass to fall through whilst keeping the goosegrass on top.' Further separation is carried out on the cylinders which separate by length. At this stage an awnless goosegrass seed cannot be separated from ryegrass seeds as they are the same length.

Other weeds which can be very difficult to remove include:

Thistles (Californian, nodding and winged, especially in a dry season).

Ryegrass off-types (these are similar in size and weight).

Hair grass (it is inclined to bridge and be carried along with good seed).

Sweet vernal (this can be trapped by covering the screens with sacking or some other material in which the vernal gets caught. This method is effective, but does reduce the efficiency of the machine as the screening area is reduced).

Wild oats (healthy wild oat seeds are relatively easy to remove, whereas oats that have been sprayed often produce a smaller, finer seed that is very similar in size to ryegrass seed and extremely difficult to extract). 
It is normal practice in seed dressing operations to leave lines containing wild oats or other undesirable contaminants to be dressed last. This is because a major clean down must be carried out after these seed lots have been dressed to avoid contaminating the next seed through the machine. The result is loss of production for the processors and an increased delay in payment for the seed producer.

Bulk handling has brought about the ability to cope with large volumes of seed, but necessitates stringent control of certification, identification, and isolation. In some cases the seed processor carries out duties previously performed by Ministry of Agriculture and Fisheries such as sampling, tagging and health inspections. Regulations relating to different countries' or markets can also create problems for seed processors.

Decisions regarding packing for specified overseas buyers must be made, often before purity tests are available. These decisions include sack material (poly, hessian or jute) and weight (40kg, $25 \mathrm{~kg}$ or $50 \mathrm{lbs})$, and whether the seed line, plus whatever impurities it contains, will be acceptable in the country for which it is destined (e.g., any line containing Poa annua will not be accepted into the USA). If the wrong decision is made and the line does not meet the required standard for a particular market it will mean repacking for despatch to an alternative destination, or redressing and retesting.

The seed processor is aiming for QUALITY. Quality means improved production for the seed processor and a better financial return to the producer. Experimentation in seed cleaning allows problem weeds to be identified and action taken. Machines are being changed to cope with new cultivars - for example, the dressing of awned types compared with perennials,. and of the many new fine grasses, require more time due to setting and screen alterations, and to their similarity in size to weeds which were not previously a problem.

Management and quality achieved by ryegrass producers has shown a marked improvement in the last few years. A $30 \%$ dressing loss was acceptable a few years ago; the current average loss is around $20 \%$ for perennial ryegrasses.

The industry needs to be more aware of good management, and quality must receive a better return. The seed producer of the future will be that farmer'who can produce quality seed consistently and who has a record of good management practice. Already some firms are seeking out these high performers to take part in the multiplication of new varieties. New Zealand has long been recognised as a producer of quality seed; standards should not be compromised. There is still room for improvement both in the field and in the store. By working together and combining the skills of growers and seed processors New Zealand can produce a top quality product at a competitive price. 